\title{
Computer aided cutting in Indian garment industry: a change agent
}

\begin{abstract}
Once under cottage industry, Indian garment Industry has come a long way since its consolidation as an industry. Today the Textile industry is one of the largest employment providing sectors and Readymade Garment manufacturing is a major chunk of it. The government of India and the state Governments keep providing their support to this sector through the policies and budgets. The transformation from a cottage industry to an organised sector has been a long journey for the Garment Industry. Readymade garments in India dropped its image from being ill-fitted tailormade clothing to the professional well-cut and tailored superbly finished ones. This major shift is contributed by multiple factors like high investment, awareness, skilled people, liberal Government policies and a very revolutionary factor, that is, use of Information Technology. Use of IT in the industry has seen a constant growth in terms of intervention to different departments of the manufacturing starting from the clerical and accounts job to the extent of artificial intelligence. The journey from the excel sheet to robotics and artificial intelligence is an interesting and encouraging one. The cutting room in a garment-manufacturing unit is a vital department where a lot of saving can be done in terms of time and raw materials both. The intervention of IT in the cutting room is pervasive throughout the industry. Hardly any manufacturing unit can think of not using Computer-aided pattern making, grading and marker making. The Apparel Computer-aided design (CAD) tool provides a great ease to the cutting department and saves a lot of money and time. This paper is an effort to underline the importance and roles of Apparel CAD in garment manufacturing. Solutions provided and the preferred solution providers in the Indian market are the focus of the study.
\end{abstract}

Keywords: apparel cutting, apparel CAD system, saving resources, high productivity
Volume 5 Issue I - 2019

\author{
Bikas Agrawal,' Dibyendu Bikash Datta² \\ 'Assistant Professor, Department of Fashion Technology, \\ National Institute of Fashion Technology, India \\ ${ }^{2}$ Associate Professor, Department of Fashion Management \\ Studies, National Institute of Fashion Technology, India
}

Correspondence: Dibyendu Bikash Datta,Associate Professor, Department of Fashion Management Studies, National Institute of Fashion Technology (Ministry of Textiles, Govt. of India), Plot3B, Block-LA, Sector III, Salt Lake City, Kolkata - 700 098, India, Tel 94333270 I9, Email dbdatta@gmail.com

Received: December 03, 2018 | Published: January 22, 2019

\section{Introduction}

Indian Apparel manufacturing is clearly divided between organized and unorganized sectors. While the big manufacturers like Arvind, Madura, Park Avenue, Monte Carlo and leading exporters like Shahi Exports, Orient Craft, Richa Global, Gokaldas Exports, Pearl Global etc. (the list of domestic and global supplier is much longer) are running their business in an organized manner and have invested lot of money in technology, each of the garment manufacturing hubs in
India have small manufacturers who generally work as the vendors to some of the exporters and also cater to domestic markets, running with low capital having less use of advanced technology. The industry is now talking about 'Industry 4.0', a name given to the current trend of automation and data exchange in manufacturing technologies. It includes cyber-physical systems, the Internet of things, cloud computing and cognitive computing. Industry 4.0 is commonly referred to as the fourth industrial revolution (Figure 1).

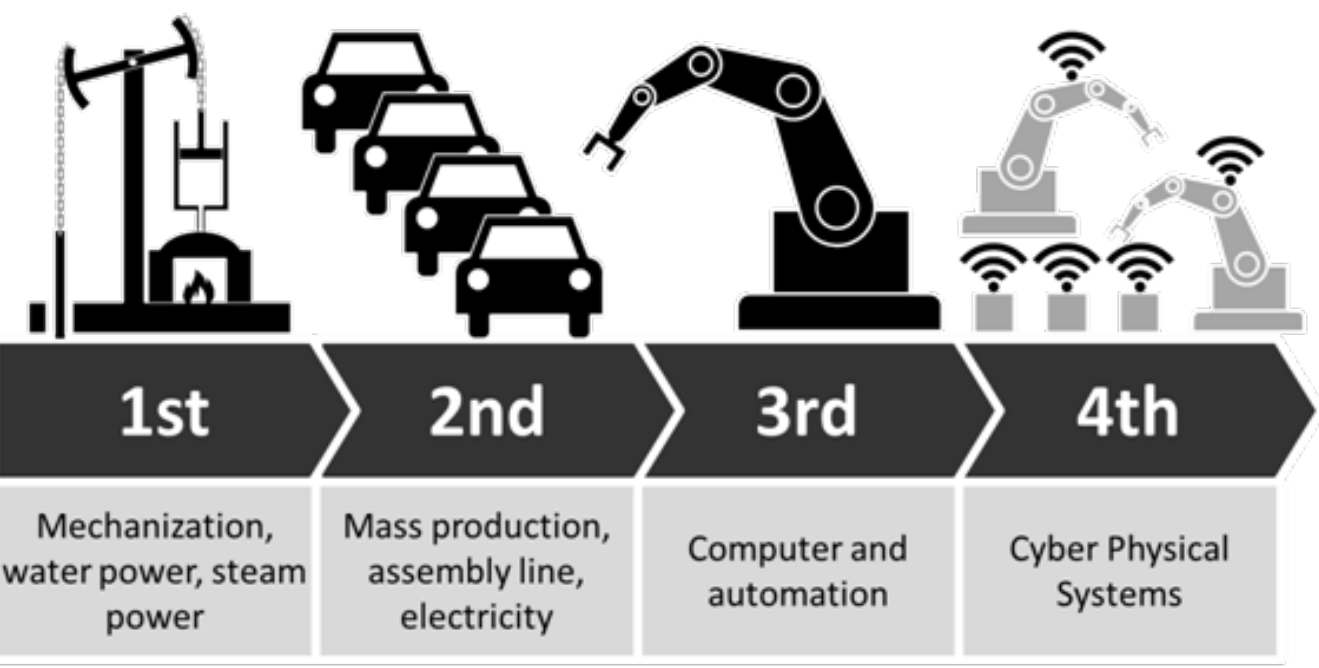

Figure I Concept of Industry 4.0 revolution. 
Apparel manufacturers, too, have been using various technologies driven by Information Technology. Use of IT tools in apparel manufacturing gives a cutting edge in terms of quick product development, consistent quality and faster dispatch of goods. Reduction in time to develop different garment samples is of utmost importance as the manufacturer has to display its product basket each fashion season and the growing competition does not allow the manufacturer to act slowly. "Product development is the oxygen of any apparel business. The objective is very simple: reduce the time it takes to develop products. Tuka 3-D and global collaboration via Tukacloud brought it down to 6 days from 90 days" says Ram Sareen, the founder of Tukatech, one of the leading company which provides apparel cutting solution worldwide and is one of the leading solution providers in India, too. The kind of reduction in time, Ram Sareen claims his software solution can do, is amazing indeed. Leveraging use of IT for emerging India has to be recognized in the sectors where India has a good growth potential. Further discussion on the topic will give more clarity (Table 1).

Table I Brief on the leading CAD software

\section{GERBER}

TECHNOLOGY https://www.gerbertechnology.com/

A made-to-order solution for manufacturers of custom clothing. Uses true automation from pattern modification to order creation to help you deliver perfectly fitting garments in record time.

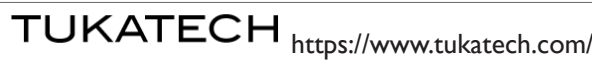

TUKATECH is an innovative apparel pattern design software that is perfect for manufacturers and designers of any size. Operating under Microsoft Windows, it allows the user to accurately build patterns, grade rules and markers for single styles or entire lines.

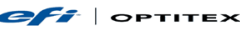

https://optitex.com/

Optitex develops 3D virtual prototyping and 2D CAD/CAM pattern and fashion design software that is innovative and easy-to-use.

\section{LECTRA. https://www.lectra.com/en}

Lectra is a technology company headquartered in Paris, France. Lectra specializes in CAD software and CAM cutting-room systems for industries using soft material such as leather and textiles. It operates in 30 countries with 32 subsidiaries.

\section{assyst}

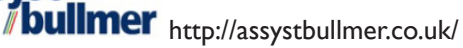

A UK based CAD software for fabric and material cutting machines for apparel and fashion, upholstery, and other applications. Body scanners can be used for made to measure garments.

Can design pattern and grading in computer or digitizing existing patterns into computer, including grading existing patterns.

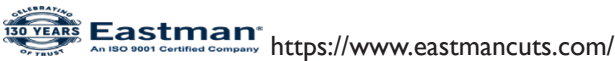

Manufacturer of hand-held and manually-operated fabric cutting machines; as well as a comprehensive line of fully automated, computerized cutting and plotting systems. Eastman has a solution for virtually every cutting requirement based in Buffalo, New York, USA.

The largest range of solutions for the cutting room. We produce several types of roll loading and handling systems, automatic spreaders,
spreading tables, labellers, automatic cutters with different lay thickness, from 2,5 to $9 \mathrm{~cm}$ and plotters. Software for CAD, Cut Order
Planning, PDM and Virtual Fitting.

\section{Objective}

The main objective of this paper is to underline the fact that use of Information Technology in the cutting room apparel manufacturing can enhance the productivity to a great extent, thus contributing in total growth of Indian industry. The paper also searches the apparel CAD solutions that are mainly used by Indian apparel manufacturers.

\section{Methodology}

Methodology in writing of this paper is secondary and primary research both. As the secondary research, published articles/papers, books related to textile and apparel manufacturing, websites of the apparel CAD solution providers are studied and as the primary study, interviews of people working in the cutting rooms of various garment manufacturers in India are taken. The primary study helps in finding out which CAD systems are prevalent in the Indian apparel industry and what exactly they are used for. Since the CAD systems provide multiple solutions, it is helpful to understand which part(s) of the systems is/are being used more. Manufacturers from the NCR, Bangalore, Chennai, Tirupur, Coimbatore, and Kolkata are covered in the study of the use of apparel CAD in the cutting room.

\section{Literature survey}

To understand the need for apparel CAD in apparel manufacturing, it is of utmost importance to know the history of apparel cutting and to know how it gradually reached its automated form at present. Various published books are read for understanding and references of the relevant terminologies are mentioned below: 
Garment cutting in earlier days: Before the mid of nineteenth century, garments were made by the tailors as per the customer's demand and specifications. The invention of sewing machines facilitated the beginning of ready to wear clothing. The British tailors started coming up with their drafted paper patterns with given size sets. An organized workforce was the driving force behind the rising demand of ready to wear garments. The gradual development of the clothing industry was seen during the nineteenth and twentieth century when developments in the field of sewing machines, cutting machines and other manufacturing facilities were seen (Figures 2-4).

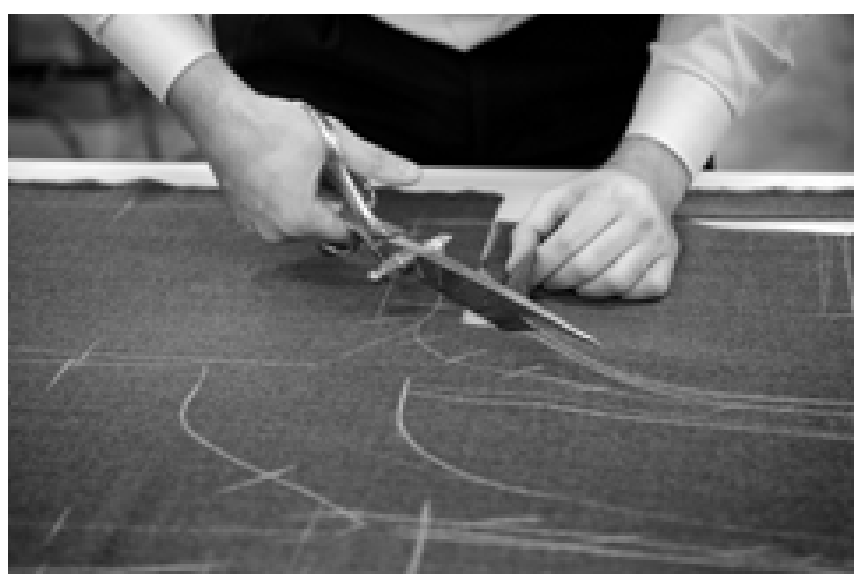

Figure 2 Manual cutting.

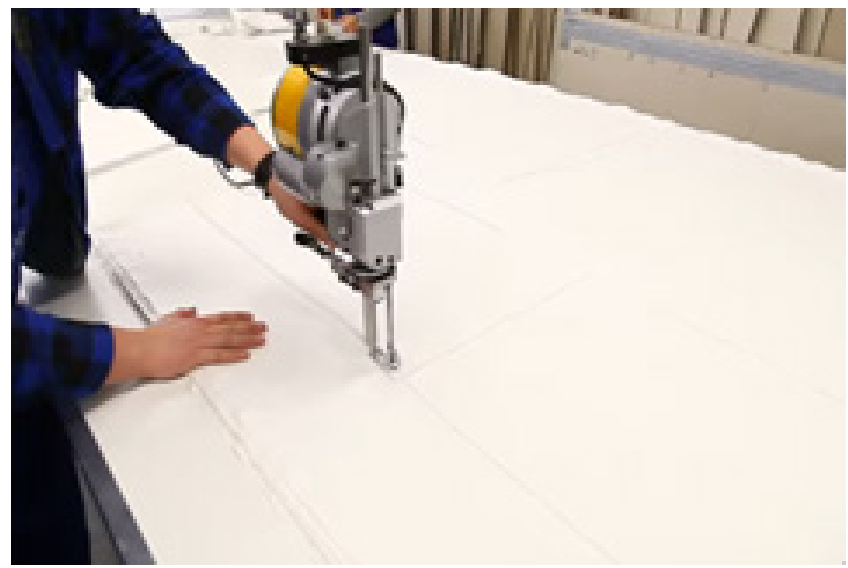

Figure 3 Machine cutting.

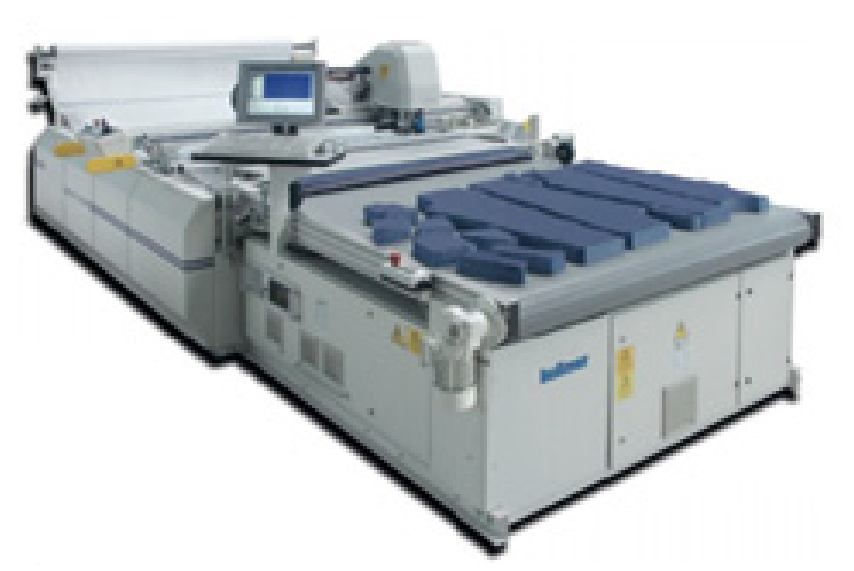

Figure 4 Automatic cutter PROCUT from Bullmer.
Size charts were a major tool that changed the mass production scenario. Ironically, wars fought during these days posed the demand for generating size charts for the organized armed forces, which later were refined for many more categories and helped in standardizing ready to wear garments (Aldrich, 2000; Nayak, \& Padhye, 2015). ${ }^{1,2}$

Till date, 14 countries have successfully completed national sizing surveys, including the USA, Canada, Mexico, the UK, France, Spain, Germany, Korea, China and Australia. Indian apparel industry uses size charts which are tweaked versions of size charts of other countries so returns of the garments are in the range of 20 to 40 per cent and is increasing with the growth of e-commerce and the main reason for returns are poor garment fit (Wright, 2018). ${ }^{3}$ A Project was sanctioned by the Ministry of Textiles, Govt. of India, under the Research and Development Scheme to develop Indian size charts based on body measurements of Indian population for better fitting of ready to wear garments. The project 'India Size' plans to measure 25,000 persons aged from 18 to 65 years in six different regions of India using 3D body scanners. It is expected that the retail garment industry will be hugely benefitted from the outcome of the project. The surveys entail measuring statistically relevant sample size pan country, using human safe technology of 3D whole body scanner, a non-contact method of taking body measurements and analysing the collected data to create size charts. Indians can finally look forward to clothes that fit. (NIFT,2018). ${ }^{4}$

Pattern making: The first stage of garment manufacturing is cutting all the parts of a garment on paper. These shapes on paper or patterns are in 2- D form and are the replicas of various parts. These patterns guide in cutting the fabric in the given shape and when they are cut and sewn according to the desired shapes, the 3-D shape of garments take place.

Marker planning: Marker making is the arrangement and marking of all the patterns required to complete one garment or a set of multiple sizes in order to achieve required technical specifications like the final appearance, hang and drape of the garment and to achieve economy of fabric consumption. Markers can be made on papers manually and the industry started making markers manually for the mass production, computer-aided markers were developed later. It is a creative and open process, as it does not have a final solution. It may have a further possibility to better itself. The markers are used for cutting multiple layers of fabric at one go to speed up the production. (Carr, Latham, David, 1994). ${ }^{5}$

Computer aided design in the cutting room: Computer-aided pattern making is the computerized version of hand-drawn patterns. There are many software companies across the globe that provides their apparel CAD solution. Apparel CAD systems were introduced in the early eighties of the twentieth century and have seen a rapid growth hence. Main functions of the complete CAD package are pattern making, digitizing of patterns, pattern grading, and marker making, and plotting. (Glock \& Kunz, 2000). ${ }^{6}$ Latest versions of CAD systems are 3-D trials and scanning of patterns by a camera that has a potential to replace digitizing boards. The functions of apparel CAD systems are mentioned above are briefly explained below:

(i) Making the first patterns: First patterns according to the garment styles are developed on the computer. The CAD system provides the working area and required tools for drawing straight lines, curvatures, pleats, darts, button, notches etc. With a basic training, the operator can start working on the system and can gradually learn all the tools provided in the 
system. Measurements of curvatures are accurate and matching of seams and curvatures of two mating parts is much easier in CAD system.

(ii) Digitization of patterns: Digitization is the process of feeding the paper patterns in the memory of the computer through the digitizing boards and digi pens or digital mouse. The digitized patterns are retrieved for modifications and adaptations of further styles. Now a company like Gerber and Lectra are coming up with their scanning cameras, which are making the process of digitization of paper patterns easier and faster. Chance of errors in capturing the exact contour of patterns is comparatively less. (Gerber, 2018). ${ }^{7}$

(iii) Grading of different sizes: "Apparel Grading is the process of increasing or decreasing the base size pattern according to a set of body measurements and proportion relationships to develop a range of sizes for production", (Bye et al. 2008). ${ }^{8}$ This process was accomplished manually before the use of computers in apparel industry but with the apparel CAD systems available in the market, Grading of the base size is done in a computer now, which still needs a lot of expertise to be accurate. With correct understanding and practice, it can be executed with precision. Grading of fullness and suppressions like pleats and darts can also be done with accuracy and with ease.

(iv) Marker making: Marker making in a CAD system is a simple and useful technique that facilitates easy and fast correction of the marker without any kind of paper wastage. The screen of the computer provides a scaled-down work area that takes care of factors like fabric width and surface design of the fabric to be cut. The operator can place the patterns with the help of the mouse in the marker area and can change the location of patterns as much time as he/she wants before being satisfied. Any type of error is captured by the system and signal generates visually as well by audio signals. All apparel CAD systems also provide the facility of auto markers, which are generated by the computer.

(v) 3-D trials: the 3-D trial room is comparatively a newer addition in the apparel CAD systems. It simulates the look of the garment on a virtual model that can be rotated easily for observing the drape of the fabric, hang and fit of the garment. If any error is found, corrections can be made in the pattern and the fit and hang can be checked again. 3-D trials save a lot of time and help in a quick response in the sampling room. (Loker, 2007). ${ }^{9}$

Computer-aided design processes are followed by computer-aided pattern plotting, spreading and cutting that is the CAM part of the total system. The apparel manufacturer may or may not take help of spreading and cutting facilities of the CAM that requires a huge amount of investment and has a very high productivity, which might not be viable for small manufacturers.

\section{Discussion and findings in industry}

About 25 apparel-manufacturing companies where apparel CAD software is being used were surveyed to know how apparel CAD is serving them in achieving various benefits. Also, the survey helped in finding out who are the market players in this field. It was found that Gerber Technology, TUK Acad, Optitex, Lectra, Assyst Bulmer, Richpeace, Eastman Pro and Morgan Technica Apparel CAD solutions are being used. Optitex is found to be very popular among the systems mentioned above but it requires another study to check the market share of companies. There are other companies who provide the solution but the above-mentioned companies are found in the surveyed companies. Some of the companies mentioned that they are using pattern making, grading and marker making modules only and are not using the digitization of patterns as they feel it is not required since they develop new patterns according to the styles given per season and small variations in a similar style they directly execute in the saved pattern file. Some of the companies are using digitizing of paper patterns along with doing all other three functions namely Pattern Making, Grading and Marker Making. Among the studied companies, some of the larger manufacturing companies are also using the computer-aided cutting that does not even require plotting of markers on paper. All the companies invariably do plotting of patterns and markers. Computer-aided cutting is an expensive solution that is the part of CAM and hence the small manufacturers do not find it economically viable. The representatives of the companies mentioned the following benefits of using CAD systems:

(i) Higher productivity: As the systems provide a high pace in creation of the patterns, grading and marker making, productivity in sampling department and the cutting department is found to be much higher in comparison to the manual process.

(ii) Easy correction: Correction of patterns and markers can be done without any sort of paper wastages as the system provides correction tools and the errors are highlighted by the systems themselves

(iii) The higher efficiency of marker making: Marker efficiency (better utilization of fabric) is higher in CAD markers as the screen provides a clear scaled down view and the smaller patterns can be fitted into the gaps generated by placements of larger patterns. Facility of auto marking in all the systems is an added advantage; it gives a comparison between the marker made by the operator and the one generated by the system, thus indicating further possibilities of more efficient markers.

(iv) Accuracy in pattern making: Dimensions in CAD software are perfect and leads to accurate measurements of curved lines, which is not easy to achieve manually. The matching neckline of body and collar with perfection is a challenge if the patterns are made manually and a lot of trial and error has to be done before finalizing the pattern. Same is the case with matching armholes of the body part and the sleeve. The Apparel CAD software provides tools to make the adjacent patterns and the mating patterns with perfect measurements and hence saves the time of hit and trial before reaching the perfect patterns. The main benefit here is that all the corrections can be done in virtual patterns and after the satisfactory results are achieved, the perfect patterns can be plotted.

(v) Easy and accurate grading: As the Grading process needs a lot of skill and accuracy in taking measurements, it is easier to develop graded size in CAD systems. The unit of measurements is perfectly applied here while in manual grading even the thickness of pencil can lead to an inaccurate size. Grading darts and other fullness like pleats and gathers can be done easily with some amount of practice and understanding.

(vi) Easy marker planning in fabrics having various surface designs: If marker making is done manually on the fabrics having surface designs like checks, stripes, woven patterns, prints etc., lot of care is needed in order to place the patterns 
correctly on the desired area of the fabric, if done carelessly, the appearance of the ready garment can go wrong. In case of CAD markers, the surface designs can be simulated on the work area of computer and accordingly the patterns can be placed without error.

(vii) Less dependence on manual work: Training in CAD is comparatively much quicker and requires less manual skill. Manual pattern making needs a lot of skill in drawing various types of curvatures, which is comparatively much easier in the CAD system. Absenteeism of the master pattern maker in case of manual pattern making is a big hindrance in high productivity. As computer training is easier, alternative persons can be trained easily. ${ }^{10,11}$

\section{Conclusion and further scope}

The Industry survey on the apparel CAD systems underlined the benefits of the use of the same in terms of productivity, quality, efficiency etc that helps to develop the business and attracts new customers. Reduction in lead-time is a great advantage, which provides the manufacturer a much-needed breathing space in the evergrowing competitive market. However, there is a further scope for the study to find about the market share and growth of CAD companies in the Indian market and the reasons for the popularity of the more accepted system. It is important to know how rapidly the apparel Industry is responding to the intervention of Information Technology in the cutting room. Another vital thing remains in the scope is a requirement of investments and return on investments.

\section{Acknowledgments}

None.

\section{Conflicts of interest}

Author declares there is no conflicts of interest in publishing the article.

\section{References}

1. Aldrich W. Tailors' cutting manuals and the growing provision of popular clothing 1770-1870 'Falling apart like a ready-made'. Textile history. 2000;31(2):163-201.

2. Nayak R, Padhye R. Introduction: the apparel industry. Garment manufacturing technology. 2015:1-17.

3. Wright B. India to use 3D body scanners in national sizing survey.

4. NIFT. National Sizing Survey of India/India Size project. National Institute of Fashion Technology.

5. Carr H, Latham B, David J Tyler. The technology of clothing manufacture. Oxford: Blackwell Scientific Publications; 1994.

6. Glock RE, Kunz GI. Apparel manufacturing: Sewn product analysis. Upper Saddle River, NJ: Prentice Hall; 2000.

7. Gerber. AccuScan Pattern Digitizing.

8. Bye E, LaBat K, McKinney E, et al. Optimized pattern grading. International Journal of Clothing Science and Technology. 2008;20(2):79-92.

9. Loker S. Mass customization and sizing. Sizing in clothing, USA: Cornell University; 2007:246-263.

10. Aldrich W. Metric pattern cutting for menswear. John Wiley \& Sons; 2011.

11. Volino P, Magnenat-Thalmann N. Virtual clothing: theory and practice Springer Science \& Business Media; 2012. 